\title{
ZURÜCK AUF START
}

\section{BACK TO START}

\section{Dear Reader,}

Hannover will once again become the focal point for agricultural technology in November. The exhibition grounds are the venue for Agritechnica, which sees itself as the world's leading international exhibition for agricultural machinery and equipment. The event is supplemented by the "Land.Technik" congress, which is held on the Friday and Saturday before the show begins. Designers and developers from major companies and institutes will already meet there to exchange the very latest information.

The trend report on Agritechnica 2011 ended with the conclusion: "Further developments in the fields of electronics, sensors and software are impressively determining agricultural innovations and leading to increasing automation of working processes in plant production with the aim of making work more efficient, more precise, more environmentally friendly and more cost-effective." According to Prof. Dr. Karlheinz Köller from the University of Hohenheim, this statement also applies "without limitations to this year's Agritechnica". This is similarly expressed, of course, in the innovations competition that takes place at the show. Almost all of the approximately 400 submissions include further developments in the fields of electronics and sensors.

The show will, however, also be characterised by the unveiling of machines that comply with the Stage IV emissions standard. This has been the focus of attention for suppliers of exhaust aftertreatment systems and manufacturers of engines and machines for several years - and there is still no end in sight. Even today, there is a fierce debate on the introduction of limit values for particle numbers. In our interview on page 25, Prof. Thomas Herlitzius calls the emission standards "a sad example of legislators attempting to do the right thing, but completely failing to hit the target." For him, what counts is cutting $\mathrm{CO}_{2}$ emissions in agricultural machines. And this can only be achieved by reducing fuel consumption. "Tier 4 has been counterproductive, because the exhaust gas aftertreatment systems and the resulting increase in fuel consumption have actually increased $\mathrm{CO}_{2}$ emissions," according to the professor of agricultural engineering.

Therefore, if legislation were to be introduced on reducing $\mathrm{CO}_{2}$ emissions in agricultural machines, current solutions would perhaps need to be completely revised. That would perhaps mean: back to start. 